\title{
Essais précliniques sur un vaccin contre la fièvre de Lassa
}

\author{
L Banadyga', DR Stein ${ }^{1,2}$, X Qiu $^{1,2}$, D Safronetz ${ }^{1,2, *}$
}

\section{Résumé}

Le virus Lassa constitue une menace persistante pour la santé à l'échelle mondiale et est responsable d'environ un demi-million de cas de fièvre de Lassa chaque année en Afrique occidentale. Bien que la plupart des cas soient légers, la maladie entraîne une morbidité importante et jusqu'à 5000 décès par année. Depuis 2015, le Nigéria est aux prises avec une éclosion grave et étendue de fièvre de Lassa, ce qui laisse craindre un débordement dans d'autres pays atteignant l'ampleur de l'éclosion du virus Ébola en Afrique occidentale de 2013 à 2016. Malgré le fardeau qu'impose la fièvre de Lassa en matière de santé publique, tant en Afrique qu'ailleurs dans le monde, il n'existe toujours pas de traitement ni de vaccin approuvés sur le plan clinique pour traiter ou prévenir la maladie. Néanmoins, des candidats-vaccins prometteurs ont été mis au point au cours des dernières années, et des efforts politiques et sociaux grandissants sont déployés pour favoriser l'homologation d'au moins un de ces candidats.

Cet article décrit un candidat-vaccin contre le virus Lassa en cours de mise au point par le Laboratoire national de microbiologie du Canada. Élaboré à partir du virus vivant atténué de la stomatite vésiculaire (VSV) utilisé comme base vaccinale pour produire un vaccin efficace contre le virus Ébola, le vaccin contre le virus Lassa à base de VSV suscite une réponse immunitaire puissante et protectrice contre le virus Lassa. En effet, le vaccin confère une protection à $100 \%$ chez le modèle primate non humain « de référence " pour la fièvre de Lassa, induisant des réponses immunitaires humorale et cellulaire. En outre, des études ont montré qu'une seule dose du vaccin offrirait une protection universelle contre de nombreuses souches du virus. Selon d'autres études, l'immunité pré-existante au VSV ne semble avoir aucune incidence sur l'immunisation utilisant le VSV comme base vaccinale. La prochaine étape de la mise au point du vaccin contre le virus Lassa à base de VSV est l'évaluation de l'innocuité et la détermination de la posologie du vaccin dans le cadre d'essais cliniques de phase I chez l'humain.

\author{
Affiliations \\ ${ }_{1}^{1}$ Programme des zoonoses et \\ pathogènes spéciaux, Laboratoire \\ national de microbiologie, \\ Agence de la santé publique du \\ Canada, Winnipeg (Manitoba) \\ 2 Département de microbiologie \\ médicale et des maladies \\ infectieuses, Université du \\ Manitoba, Winnipeg (Manitoba)
} *Correspondance : david.
safronetz@canada.ca

Citation proposée : Banadyga L, Stein DR, Qiu X, Safronetz D. Essais précliniques sur un vaccin contre la fièvre de Lassa. Relevé des maladies transmissibles au Canada 2018;44(6):155-64.

https://doi.org/10.14745/ccdr.v44i06a04f

Mots-clés : virus Lassa; fièvre de Lassa; virus de la stomatite vésiculaire; vaccin; essais précliniques

\section{Introduction}

L'éclosion du virus Ébola de 2013 à 2016 en Afrique occidentale a démontré qu'une éclosion survenant à un endroit donné peut représenter une menace partout (1). Responsable de près de 29000 cas et de plus de 11000 décès, le virus Ébola a ravagé la Sierra Leone, le Libéria et la Guinée, et la maladie s'est finalement propagée dans de nombreux pays avoisinants et dans certains pays occidentaux, dont les États-Unis (2). Par ailleurs, l'éclosion a non seulement détruit l'infrastructure de santé publique de l'Afrique occidentale, mais aussi mis à rude épreuve les interventions mondiales de santé. En effet, des milliers de travailleurs de la santé du monde entier ont été déployés en Afrique occidentale, où ils ont supporté un fardeau disproportionné et où plus de $50 \%$ des personnes infectées par le virus Ébola ont succombé à la maladie (3). L'ampleur et la gravité de cette éclosion sont dues en partie à l'absence de traitement approuvé sur le plan clinique ou de vaccin pour la prévenir.
À la suite de l'éclosion du virus Ébola ainsi que celle du virus Zika en 2015, la Bill and Melinda Gates Foundation a reconnu la nécessité d'avoir des capacités de pointe en matière de préparation en cas d'épidémie à l'échelle mondiale. En collaboration avec le Wellcome Trust, le Forum économique mondial et les gouvernements de la Norvège et de I'Inde, la Bill and Melinda Gates Foundation a mis sur pied la Coalition for Epidemic Preparedness and Innovations en 2016. Le principal objectif de cette coalition était de financer la mise au point de vaccins prometteurs contre les agents pathogènes émergents pouvant causer d'importantes éclosions dans un avenir proche, afin d'accélérer le processus menant aux essais cliniques de phase III en cas d'éclosion. Un des agents pathogènes retenus pour le financement et le développement accélérés par la Coalition était le virus Lassa. 
Le virus Lassa, un virus à acide ribonucléique (ARN) monocaténaire enveloppé de la famille des Arenaviridae, est responsable de la fièvre virale hémorragique appelée fièvre de Lassa. Habituellement, le virus se transmet par l'exposition à I'urine ou aux excréments de rats du Natal infectés, quoiqu'il puisse aussi se propager d'un humain à l'autre par contact direct avec du sang, de l'urine, des excréments ou d'autres sécrétions organiques contaminées. Après une période d'incubation d'une à trois semaines, la maladie se manifeste par l'apparition graduelle de fièvre, de malaise et de douleurs musculaires et articulaires. À mesure que la maladie évolue, la fièvre et la myalgie s'intensifient, et les patients peuvent se retrouver dans un état de prostration. La diarrhée, les vomissements et d'autres perturbations gastro-intestinales sont courants, tout comme la douleur rétrosternale et la toux. Les manifestations hémorragiques sont peu fréquentes, mais évoquent un pronostic défavorable. II en va de même pour l'œdème du visage et l'épanchement pleural. Les cas les plus graves mènent au choc et au décès, tandis que dans les cas non fatals, qui se résolvent au bout de deux à trois semaines, la surdité est courante et souvent permanente (4).

On compte environ 300000 à 500000 cas de fièvre de Lassa en Afrique occidentale chaque année, ce qui en fait une des fièvres virales hémorragiques les plus prévalentes chez l'humain $(5,6)$. Bien que seulement 1 à $2 \%$ de ces cas soient mortels, l'ampleur des infections porte le nombre global de morts à plusieurs milliers par année. La fièvre de Lassa se limite surtout aux pays de l'Afrique occidentale, à savoir la Sierra Leone, le Libéria, la Guinée et le Nigéria; cependant, des cas d'infection par le virus Lassa qui se propage ailleurs dans le monde, parallèlement aux cas de transmission entre humains, ont été largement documentés (7-10). Depuis 2015, le Nigéria est aux prises avec une éclosion prolongée de fièvre de Lassa, ce qui fait craindre une autre épidémie pouvant rivaliser avec la portée de l'éclosion récente du virus Ébola en Afrique occidentale. Depuis le début de 2018, le virus Lassa est à l'origine de milliers de cas soupçonnés, de 413 cas confirmés, de 9 cas probables et de 114 décès. En comptant les cas confirmés et probables, I'éclosion survenue au Nigéria est liée à un taux de mortalité extrêmement élevé, soit de 25 \% (11).

Malgré le fardeau important qu'impose le virus Lassa en matière de santé publique dans le monde, le virus demeure sous-étudié, sans aucun traitement ni vaccin approuvé. Néanmoins, plusieurs candidats-vaccins contre le virus Lassa ont été retenus et doivent être testés dans des essais cliniques, y compris le vaccin contre le virus Lassa en cours de mise au point par le Laboratoire national de microbiologie (LNM) du Canada. Ce vaccin est fabriqué à partir d'un virus de la stomatite vésiculaire (VSV) réplicatif qui s'est avéré extrêmement efficace chez les modèles animaux de fièvre de Lassa. Dans cette présentation générale, nous traiterons des essais précliniques sur le vaccin contre le virus Lassa à base de VSV dans le contexte du vaccin contre le virus Ébola mis au point à partir de la même base vaccinale. Nous décrirons aussi d'autres candidats-vaccins prometteurs contre le virus Lassa.

\section{Contexte}

\section{Virus de la stomatite vésiculaire comme base vaccinale}

Les vaccins les plus efficaces sont habituellement fabriqués à partir d'un virus vivant atténué. Ces vaccins, comme le vaccin contre la rougeole, sont souvent plus efficaces pour induire une réponse immunitaire protectrice et une immunité durable que les vaccins viraux inactivés ou sous-unitaires. Une des démarches adoptées pour créer des vaccins vivants atténués repose sur l'utilisation d'un "squelette " viral relativement inoffensif comme base vaccinale pour transporter les antigènes d'un autre virus plus pathogène. Au LNM, nous travaillons avec le VSV comme base vaccinale pour divers virus, dont le virus Ebola, le virus de Marburg (MARV) et le virus Lassa.

Les vésiculovirus ont leur propre genre au sein de la famille des Rhabdoviridae et causent des maladies principalement chez les mammifères et les poissons (12). Dans I'hémisphère occidental, deux vésiculovirus prédominent : le virus de la stomatite vésiculaire de sérotype Indiana et le virus de la stomatite vésiculaire de sérotype New Jersey (13). Les deux VSV sont transmis par des insectes et causent la stomatite vésiculaire chez le cheval, le bétail et le porc, qui se traduit par l'apparition de lésions érosives sur la langue, les gencives, les lèvres, les sabots et les mamelles des animaux infectés (14). Chez l'humain, I'infection par le VSV est aussi possible, mais peu fréquente et peut ressembler à une grippe spontanément résolutive avec ou sans lésions vésiculaires (15-17). Étant donné que son tableau clinique est comparable à celui de la fièvre aphteuse chez les animaux d'élevage, le VSV est considéré comme une maladie à déclaration obligatoire par le gouvernement du Canada.

L'élaboration d'un système permettant de concevoir un nouveau VSV recombinant à partir d'ADN plasmidique $(18,19)$ a grandement augmenté I'utilité du VSV comme base vaccinale (20). Le VSV de type sauvage possédait déjà plusieurs qualités qui le rendait approprié comme vecteur de vaccin, et la capacité de concevoir un VSV recombinant en a seulement augmenté l'utilité. Le génome du VSV tolère I'ajout de nombreux transgènes de grande taille, qui servent $d$ 'antigènes vaccinaux $(21,22)$, et le virus en soi est capable de se répliquer de manière à atteindre des titres plus élevés dans divers types de cellules (23-25), ce qui facilite la production de vaccins. Par ailleurs, I'infection par le VSV induit de fortes réponses humorale et cellulaire (26-28), favorisant ainsi une réponse immunitaire robuste contre le transgène incorporé; l'immunité pré-existante chez l'humain étant rare (15-17), l'efficacité du vaccin se trouve maximisée. En outre, le VSV se réplique dans le cytoplasme sans intermédiaire ADN, ce qui exclut la possibilité d'une recombinaison génétique avec la cellule hôte. Le génome du VSV n'étant pas segmenté, la possibilité d'une transformation génétique est écartée. Par conséquent, vu le potentiel du VSV comme vecteur de vaccin sûr et efficace, il n'est pas étonnant que ce système ait été largement exploité pour fabriquer des vaccins contre de nombreux virus, notamment le $\mathrm{VIH}$ dont les premières évaluations chez l'humain sont déjà terminées (29).

Le LNM emploie une variante notable du VSV comme base vaccinale, appelée VSV $\Delta G$, car il lui manque la glycoprotéine virale $(G)$ qui favorise la pénétration du virus et sert de principal 
facteur de pathogénicité du virus. Le retrait de la glycoprotéine du VSV permet non seulement d'atténuer le virus en éliminant son potentiel infectieux au niveau du système nerveux, mais aussi d'y substituer une glycoprotéine virale analogue, ce qui entraîne une puissante réponse immunitaire dirigée contre un antigène cible important. Cette stratégie a été appliquée à la mise au point du vaccin contre le virus Ébola à base de VSV. De fait, un essai clinique de phase III de petite envergure a démontré récemment que ce vaccin est efficace à $100 \%$ contre l'infection par le virus Ébola (30). Les travaux du LNM menés sur le vaccin contre le virus Lassa sont fondés sur l'architecture du VSV $\Delta G$ (figure 1).

Figure 1 : Virus de la stomatite vésiculaire comme base vaccinale

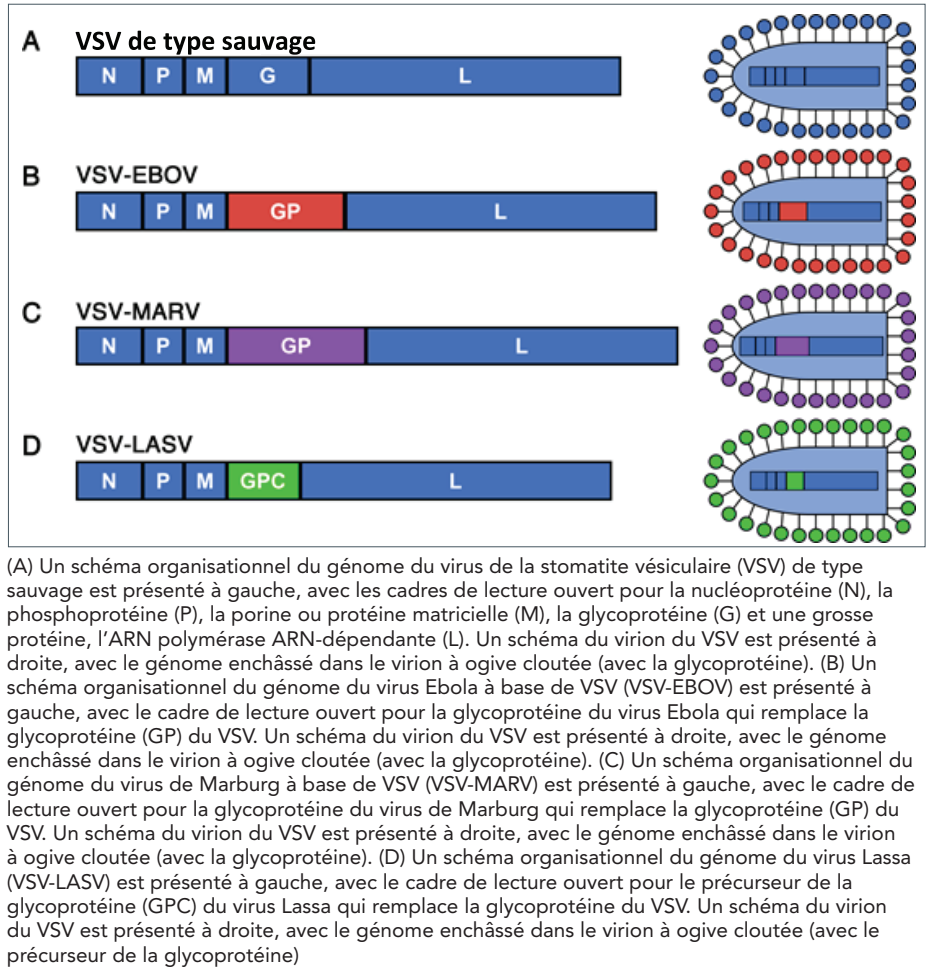

\section{Mise au point des vaccins à base de virus de la stomatite vésiculaire contre Ébola et la fièvre de Lassa}

La mise au point du vaccin à base de VSV contre le virus Lassa est étroitement liée à celle du vaccin contre le virus Ébola à base de VSV. L'origine des deux vaccins peut être retracée dans un seul article. En 2004, Garbutt et ses collègues ont publié le premier article sur les VSV réplicatifs (sérotype Indiana; VSVI) exprimant les glycoprotéines du virus Ébola, du virus de Marburg ou du virus Lassa, appelés VSV-EBOV, VSV-MARV et VSV-LASV, respectivement (31). Les trois virus présentaient une cinétique de croissance légèrement atténuée comparativement au VSV de type sauvage et exprimaient fortement leur glycoprotéine. Ils présentaient également le profil de traitement protéolytique prévu. De plus, aucun VSV n'a rendu malades les souris, ce qui indiquerait qu'ils ne sont pas pathogènes. Garbutt et ses collègues ont ensuite administré une dose mortelle de virus Ébola adapté à la souris aux trois groupes de souris 28 jours après I'inoculation initiale du VSV. Toutes les souris ont été malades et ont succombé à l'infection, sauf celles qui ont reçu le VSV-EBOV au départ. II s'agit de la première indication que le VSV peut être utilisé comme base vaccinale pour susciter une réponse immunitaire contre une glycoprotéine hétérologue qui, à son tour, peut protéger l'animal contre la maladie.

Peu de temps après la démonstration de l'efficacité du vaccin VSV-EBOV chez les souris (31), le même groupe de chercheurs a publié un article caractérisant pour la première fois le vaccin VSV-LASV chez des primates non humains (32). Des macaques de Buffon ont reçu une dose unique du vaccin VSV-LASV par voie intramusculaire. Les animaux n'ont présenté aucun signe de maladie et $n$ 'ont pas excrété le virus vaccinal, ce qui met en évidence l'innocuité de ce vecteur. Vingt-huit jours plus tard, les animaux ont été exposés au virus Lassa. Tous les animaux vaccinés ont survécu, et aucun n'a présenté de signes de la fièvre de Lassa. Le vaccin a semblé induire une réponse immunitaire à la fois humorale et cellulaire, et il n'y a eu aucune différence marquée quant aux paramètres chimiques du sang et hématologiques des animaux avant et après l'exposition au virus Lassa. Par contre, deux animaux témoins ayant reçu le vaccin VSV-EBOV ont présenté des manifestations cliniques correspondant à celles de la fièvre de Lassa et ont succombé à la maladie, sans toutefois présenter une réponse immunitaire au virus Lassa décelable. Cette étude offrait une démonstration préliminaire - mais très prometteuse - de l'efficacité du vaccin VSV-LASV; cependant, il aura fallu près de dix ans avant que des essais de suivi soient effectués.

En 2013, le virus Ébola est apparu pour la première fois en Afrique occidentale et a provoqué une éclosion sans précédent. Ce virus était désormais présent, et possiblement endémique, dans la même région géographique que celle du virus Lassa. II y avait des doutes quant à l'efficacité d'une seule base vaccinale si elle était utilisée dans des vaccins séparés contre de multiples agents pathogènes. Pour résoudre cette question, Marzi et ses collègues (33) ont administré à un groupe de trois macaques de Buffon une dose unique du vaccin VSV-LASV et ont exposé les animaux au virus Lassa 28 jours plus tard. Aucun animal n'a présenté de signes de maladie et l'absence de forte réponse des anticorps laisse penser que la vaccination a induit une immunité stérile ou quasi stérile. Soixante jours plus tard, les trois mêmes animaux ont reçu une dose unique du vaccin VSV-EBOV, puis ont été exposés au virus Ébola. Malgré des titres d'anticorps dirigés contre le VSV plus élevés au moment de la deuxième vaccination, les trois animaux bénéficiaient d'une protection complète contre I'infection par le virus Ebola et présentaient une forte réponse immunitaire. Par conséquent, l'immunité pré-existante contre le squelette du VSV n'a pas altéré l'efficacité du vaccin, indiquant que plusieurs vaccins à base de VSV peuvent vraisemblablement être utilisés au sein d'une même population.

II restait à savoir si un seul vaccin VSV-LASV permettait de prévenir la maladie causée par de multiples isolats du virus Lassa puisque celui-ci présente une grande diversité génétique parmi les virus géographiquement dispersés (34). Safronetz et ses collaborateurs (35) se sont penchés sur la question en commençant par utiliser un modèle cobaye pour l'infection par le virus Lassa, démontrant que le vaccin VSV-LASV conférait une protection complète aux animaux contre trois isolats hétérologues du virus Lassa : Z-132 (du Libéria), Soromba-R 
(du Mali) et Pinneo (du Nigéria). De même, la vaccination par le VSV-LASV a conféré une protection aux macaques de Buffon contre l'exposition mortelle à la souche Z-132 du virus Lassa. Ces résultats indiquent qu'un seul vaccin peut offrir une protection universelle contre toutes les souches du virus Lassa et peut être déployé dans toute la région où le virus Lassa est endémique, ce qui touche au moins neuf pays et des centaines de millions de personnes.

\section{Essais précliniques sur les vaccins à base de virus de la stomatite vésiculaire}

Les essais précliniques sur le vaccin VSV-LASV utilisant divers modèles animaux, dont des primates non humains, ont démontré que ce vaccin est sûr et efficace pour susciter une réponse immunitaire qui confère une protection assez large contre le virus Lassa, et ce, malgré une immunité pré-existante contre le VSV. Même si le VSV-LASV est prometteur, les essais cliniques sur ce vaccin ne sont toujours pas commencés. Néanmoins, le VSV comme base vaccinale a été largement testé avec le vaccin VSV-EBOV, qui a fait l'objet d'essais précliniques et cliniques rigoureux $(36,37)$, dont des essais cliniques de phase III chez les humains ayant démontré qu'il est efficace à $100 \%$ (30). Parallèlement, le vaccin VSV-MARV a fait l'objet de nombreux essais précliniques (38), et des vaccins à base de VSV ont été mis au point contre d'autres filovirus, dont le virus Soudan et le virus Bundibugyo $(39,40)$, qui se sont tous révélés extrêmement efficaces en prophylaxie (36-38). D'ailleurs, les travaux effectués sur les vaccins contre les filovirus à base de VSV au cours des dernières années ont grandement contribué à la compréhension de l'infection par les filovirus et du VSV comme base vaccinale.

Les recherches sur le vaccin VSV-EBOV ont démontré que la formation d'anticorps est un corrélat essentiel à la protection (41). Des études sur le vaccin VSV-MARV indiquent que l'immunité vaccinale est durable et reste efficace au moins 14 mois chez le modèle primate non humain (42). En outre, le vaccin VSV-EBOV, et par extension, le squelette du VSV $\Delta G$, s'est révélé sûr chez les animaux immunodéprimés (c.-à-d. primates non humains infectés par le virus de l'immunodéficience simienne-humaine) et les animaux d'élevage $(43,44)$. Vu le peu de protection interespèces qu'offrent les vaccins monovalents à base de VSV, des vaccins unidose trivalents et monovalents mélangés ont aussi été mis au point et se sont avérés $100 \%$ efficaces, ce qui laisse penser que le VSV comme base vaccinale peut être manipulé et optimisé pour offrir une protection contre plusieurs virus à la fois $(22,39)$. Enfin, des essais cliniques de phase I, II et III ont confirmé I'innocuité, la tolérabilité et l'immunogénicité du vaccin VSV-EBOV, et ce, même à des doses élevées $(25,30,45-49)$. Il convient de noter que des effets indésirables ont été observés dans de rares cas (30); une incidence relativement élevée d'arthrite, de dermatite et de vascularite induites par le vaccin a été signalée dans un essai clinique de phase I $(45,46)$.

\section{Évaluation du risque pour les animaux d'élevage}

L'utilisation d'un vaccin vivant à base de VSV touche non seulement les humains qui le reçoivent, mais aussi possiblement les animaux entrant en contact avec des humains vaccinés. Étant donné que l'infection par le VSV chez les animaux d'élevage est une maladie à déclaration obligatoire, I'utilisation d'un vaccin à base de VSV implique que les animaux d'élevage peuvent être touchés, ce qui peut provoquer une crise agricole ayant des répercussions réglementaires. Pour résoudre cette question, de Wit et ses collègues (44) ont inoculé des doses élevées du VSV-EBOV ou du VSV de type sauvage à des cochons et ont surveillé les animaux pour déceler des signes d'infection ou de maladie. Fait étonnant, peu importe le virus utilisé pour l'infection, une réplication virale a été décelée chez une minorité d'animaux, il n'y avait pas de virémie, l'excrétion du virus était minime et aucun animal n'a présenté de signes manifestes d'infection. Vu l'absence de maladie chez les cochons après l'inoculation directe du virus, il est peu probable qu'un humain vacciné puisse transmettre le virus à un cochon, qui causerait une infection productive accompagnée de signes manifestes de maladie. Par ailleurs, même en cas de transmission dans ce contexte, le virus vaccinal est peu susceptible de subsister au sein de la population animale. Cette étude confirme l'innocuité des vaccins à base de VSV et donne à penser que le risque pour la santé des animaux d'élevage est minime.

\section{Solutions de rechange au vaccin contre la fièvre de Lassa à base de virus de la stomatite vésiculaire}

Afin de trouver un vaccin sûr et efficace contre le virus Lassa, différentes bases vaccinales ont été mises au point au cours des dernières décennies $(50,51)$ (tableau 1$)$. Les vaccins contenant un virus de la vaccine réplicatif comme vecteur codant pour la nucléoprotéine et(ou) la glycoprotéine du virus Lassa faisaient partie des premières bases vaccinales conçues et ont démontré une efficacité raisonnable chez les cobayes et les primates non humains (52-56). Étant donné la nature immunodépressive du virus de la vaccine, cette base vaccinale a été abandonnée en cours de mise au point pour des raisons d'innocuité, surtout chez les individus immunodéprimés (51). La souche 17D du virus de la fièvre jaune (YF17D), codant pour la glycoprotéine ou des sous-unités de la glycoprotéine du virus Lassa, a aussi été utilisée dans un vaccin contre le virus Lassa, quoique son immunogénicité soit faible et peu efficace chez les primates non humains $(50,57,58)$. De même, le virus Lassa inactivé n'a pas conféré de protection contre une fièvre de Lassa mortelle chez les primates non humains (59). Les réplicons de l'arbovirus, qui sont des molécules d'ARN autoréplicables exprimant des antigènes étrangers plutôt que des protéines structurelles de l'arbovirus et enveloppées dans des particules pseudovirales, ont donné des résultats prometteurs comme vaccins contre le virus Lassa. Ils favorisent entre autres la réponse des lymphocytes T CD8+ et confèrent une protection complète aux cobayes, mais d'autres précisions doivent être apportées à leur caractérisation (60-62). Fait à noter, un vaccin contre le virus Lassa à base d'ADN a offert une protection complète contre ce virus chez les cobayes et les primates non humains, mais devait être administré plusieurs fois, ce qui ne serait pas commode dans les régions où le virus Lassa est endémique (63-65).

En plus du vaccin VSV-LASV, le candidat-vaccin contre le virus Lassa le plus perfectionné utilise comme base un virus réassorti à partir du virus Lassa et du virus Mopeia (qui serait non pathogène) $(50,51)$. Le clone ML29 possède du matériel génétique provenant du virus Mopeia et du virus Lassa notamment les gènes codant pour la nucléoprotéine et la 
Tableau 1 : Candidats-vaccins contre le virus Lassa et leur évaluation chez des modèles animaux

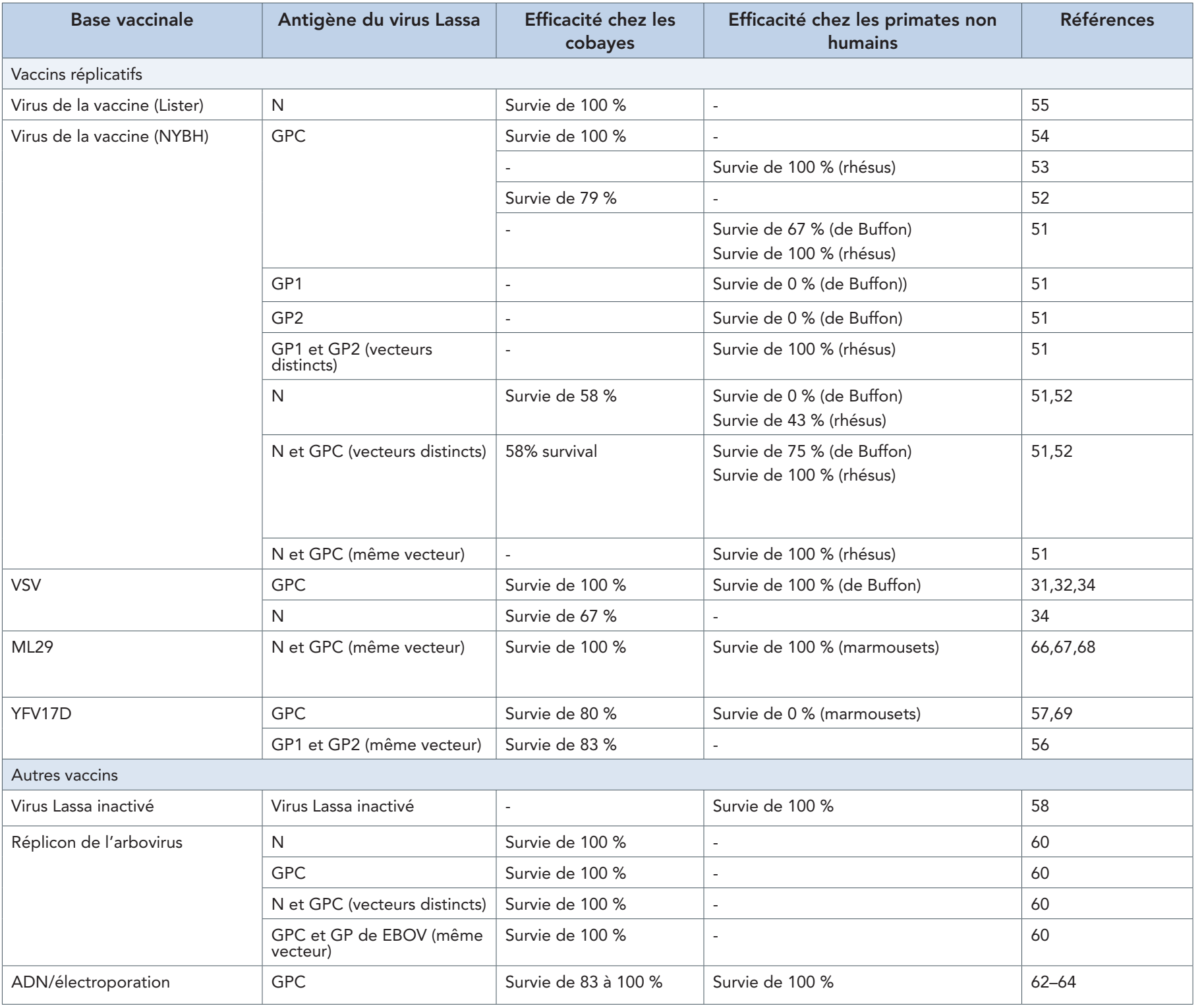

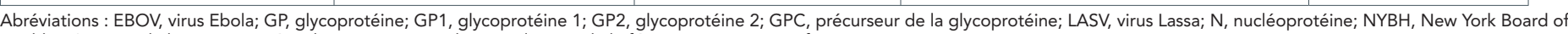
Health; VSV, virus de la stomatite vésiculaire; YF17D, souche 17D du virus de la fièvre jaune; « - ", pas fait

glycoprotéine de ce dernier - et comporte plusieurs autres mutations ponctuelles qui atténueraient davantage le virus $(66,70,71)$. La vaccination par le clone ML29 s'est révélée sûre et suscite une réponse immunitaire puissante et protectrice contre le virus Lassa. En effet, le clone ML29 offre une protection complète chez les cobayes et les primates non humains, demeure efficace lorsqu'il est administré jusqu'à deux jours suivant l'infection et est sûr chez les animaux immunodéprimés. II semble stable sur le plan génétique et n'a pas de prédisposition au réassortiment avec le virus Lassa pathogène $(67,68,70,72,73)$; cependant, jusqu'à tout récemment, le clone ML29 a été classé par les Centers for Disease Control des États-Unis comme un agent pathogène du groupe de risque 3 , indiquant que d'autres études de validation de l'innocuité seraient nécessaires.

\section{Discussion}

Le virus Lassa cause des centaines de milliers d'infections chaque année et des milliers de décès (5). Malgré la menace évidente que représente le virus Lassa en matière de santé publique, le virus et la maladie qui en résulte demeurent sous-étudiés. C'est en grande partie pour cette raison que l'Organisation mondiale de la santé a ajouté l'infection par le virus Lassa comme maladie prioritaire à son projet R\&D visant à améliorer la coordination de la recherche dans le monde, à accélérer l'élaboration de contre-mesures et à fournir un cadre d'intervention lors d'éclosions (74). Ce projet vise à établir un plan de recherche accéléré sur cinq ans pour procéder aux essais cliniques de phase III sur les vaccins contre le virus Lassa. Par ailleurs, la Coalition for Epidemic Preparedness and Innovations s'est engagée à financer la mise au point avancée de certains 
candidats-vaccins contre le virus Lassa. Cependant, les bases vaccinales qui seront retenues n'ont pas encore été annoncées.

Bien que des progrès significatifs aient été réalisés en ce qui a trait à la mise au point d'un vaccin sûr et efficace contre le virus Lassa, d'autres recherches s'imposent. Beaucoup de questions importantes concernant l'utilisation et l'efficacité du vaccin VSV-LASV restent posées, particulièrement la question du ou des modes d'action. La présence de lymphocytes T CD8+ activés a été observée chez la majorité des primates non humains ayant reçu le vaccin VSV-LASV (32), indiquant que la réponse immunitaire cellulaire jouerait un rôle important dans la protection. D'ailleurs, le contrôle de la fièvre de Lassa chez les primates non humains a été corrélé avec la circulation de lymphocytes T CD4+ et CD8+ activés (75), et les cas de fièvre de Lassa non mortels chez l'humain ont été associés à des taux élevés de chimiokines attirant les lymphocytes T (76-78). À l'inverse, la réponse humorale à l'infection par le virus Lassa ne semble pas jouer un rôle important dans la guérison de I'infection (75,79-81), et les anticorps neutralisants semblent peu mobilisés $(32,69,75,78)$. Contrairement au vaccin VSVEBOV, dans lequel les anticorps jouent un rôle essentiel en matière de protection (41), la réponse humorale ne semble pas jouer un rôle important dans la protection suscitée par le vaccin VSV-LASV; toutefois, d'autres travaux de recherche s'imposent dans ce domaine. II reste aussi à évaluer le temps écoulé avant l'immunité, la durabilité de l'immunité et l'efficacité thérapeutique post-exposition du vaccin. Enfin, l'innocuité et I'efficacité du vaccin VSV-LASV, comme dans le cas du vaccin contre le virus Ébola, chez les personnes immunodéprimées sont particulièrement préoccupantes advenant le déploiement du vaccin dans les régions où le virus Lassa est endémique et où le taux de séropositivité pour le $\mathrm{VIH}-1$ est élevé. Malgré les travaux qui restent à faire, le vaccin VSV-LASV est tout de même l'un des vaccins contre le virus Lassa en cours de mise au point les plus prometteurs.

\section{Conclusion}

Le vaccin VSV-LASV est prêt à être évalué dans le cadre d'essais cliniques. Un groupe d'experts sondés par la revue Science considèrent déjà ce vaccin comme l'un des deux candidats-vaccins contre le virus Lassa ayant le plus grand potentiel (82). En effet, le vaccin VSV-LASV offre non seulement une protection complète contre différentes souches du virus Lassa, mais sa base vaccinale, le VSV $\Delta G$, est déjà bien caractérisée. Bien que des doutes aient été soulevés quant à I'innocuité du VSV comme base vaccinale, particulièrement dans le contexte du vaccin contre le virus Ébola, la majorité des données d'essais cliniques disponibles laissent penser que le vaccin VSV-EBOV est à la fois sûr et efficace. De même, le vecteur semble peu susceptible de représenter une menace pour les animaux d'élevage.

La prochaine étape de la mise au point du vaccin VSV-LASV est l'évaluation de son innocuité et la détermination de sa posologie dans le cadre d'essais cliniques de phase I chez l'humain. Alors que le virus Lassa poursuit ses ravages en Afrique occidentale, notamment l'éclosion touchant actuellement le Nigéria, la volonté politique et sociale de mettre au point un vaccin sûr et efficace contre cette maladie est plus forte que jamais. Le vaccin VSV-LASV semble en bonne voie de faire partie de la solution afin de réduire la menace que représente le virus Lassa pour le monde entier.

\section{Déclaration des auteurs}

L. B. - Rédaction - ébauche initiale; rédaction - révision et édition

D. R. S. - Rédaction - ébauche initiale; rédaction - révision et édition

X. Q. - Rédaction - révision et édition; supervision

D. S. - Conception initiale; rédaction - révision et édition; supervision

L. Banadyga et D. R. Stein ont contribué en parts égales à cet article.

\section{Conflit d'intérêt}

Les auteurs ne signalent aucun conflit d'intérêts.

\section{Remerciements}

Les auteurs tiennent à remercier Jonathan Audet de son aide technique expert avec le manuscrit français.

\section{Financement}

Ce travail a été réalisé grâce au soutien de l'Agence de la santé publique du Canada.

\section{Références}

1. Tam T. Quinze ans après le SRAS : Principaux jalons de l'intervention en cas d'urgence touchant la santé publique du Canada. Relevé des maladies transmissibles au Canada 2018;44(5):109-12. https://www.canada.ca/fr/sante-publique/ services/rapports-publications/releve-maladies-transmissiblescanada-rmtc/numero-mensuel/2018-44/numero-5-3-mai-2018/ article-1-principales-etapes-apres-sras.html

2. World Health Organization. Ebola Situation Report - 30 March 2016. WHO: 2016. http://apps.who.int/ebola/ current-situation/ebola-situation-report-30-march-2016

3. World Health Organization. Health worker Ebola infections in Guinea, Liberia and Sierra Leone. Preliminary Report. WHO: 2015. www.who.int/csr/resources/publications/ebola/ health-worker-infections/en/

4. Buchmeier MJ, de la Torre J, Peters CJ. Arenaviridae: The Viruses and Their Replication. In: Knipe DM, Howley PM, editors. Fields Virology. $5^{\text {th }}$ ed. Philadelphia, PA: Lippincott Williams \& Wilkins; 2007.

5. McCormick JB, Webb PA, Krebs JW, Johnson KM, Smith ES. A prospective study of the epidemiology and ecology of Lassa fever. J Infect Dis 1987 Mar;155(3):437-44. http://dx.doi. org/10.1093/infdis/155.3.437. PubMed (https://www.ncbi. nlm.nih.gov/pubmed/3805771) 
6. Falzarano D, Feldmann $\mathrm{H}$. Vaccines for viral hemorrhagic fevers--progress and shortcomings. Curr Opin Virol 2013 Jun;3(3):343-51. http://dx.doi.org/10.1016/j. coviro.2013.04.007. PubMed (https://www.ncbi.nlm.nih.gov/ pubmed/23773330)

7. Ogbu O, Ajuluchukwu E, Uneke CJ. Lassa fever in West African sub-region: an overview. J Vector Borne Dis 2007 Mar;44(1):111. PubMed (www.ncbi.nlm.nih.gov/pubmed/17378212)

8. Bausch DG, Demby AH, Coulibaly M, Kanu J, Goba A, Bah A, Condé N, Wurtzel HL, Cavallaro KF, Lloyd E, Baldet FB, Cissé SD, Fofona D, Savané IK, Tolno RT, Mahy B, Wagoner KD, Ksiazek TG, Peters CJ, Rollin PE. Lassa fever in Guinea: I. Epidemiology of human disease and clinical observations. Vector Borne Zoonotic Dis 2001;1(4):269-81. http://dx.doi. org/10.1089/15303660160025903. PubMed (https://www. ncbi.nlm.nih.gov/pubmed/12653127)

9. Frame JD. Clinical features of Lassa fever in Liberia. Rev Infect Dis 1989 May-Jun;11(Suppl 4):S783-9. http://dx.doi. org/10.1093/clinids/11.Supplement_4.S783. PubMed (www. ncbi.nlm.nih.gov/pubmed/2749109)

10. McCormick JB, King IJ, Webb PA, Johnson KM, O'Sullivan $R$, Smith ES, Trippel S, Tong TC. A case-control study of the clinical diagnosis and course of Lassa fever. J Infect Dis 1987 Mar;155(3):445-55. http://dx.doi.org/10.1093/ infdis/155.3.445. PubMed (www.ncbi.nlm.nih.gov/ pubmed/3805772)

11. Nigeria Centre for Disease Control. 2018 Lassa Fever Outbreak in Nigeria (for Week 15; April 15, 2018). World Health Organization; 2018. www.ncdc.gov.ng/diseases/sitreps

12. Lyles DS, Rupprecht CE. Rhabdoviridae. In: Knipe DM, Howley PM, editors. Fields Virology. 5th ed. Philadelphia, PA: Lippincott Williams \& Wilkins; 2007.

13. Amarasinghe GK, Bào $Y$, Basler CF, Bavari $S$, Beer M, Bejerman $\mathrm{N}$, Blasdell KR, Bochnowski A, Briese T, Bukreyev A, Calisher $\mathrm{CH}$, Chandran K, Collins PL, Dietzgen RG, Dolnik O, Dürrwald R, Dye JM, Easton AJ, Ebihara H, Fang Q, Formenty P, Fouchier RAM, Ghedin E, Harding RM, Hewson R, Higgins CM, Hong J, Horie M, James AP, Jiang D, Kobinger GP, Kondo H, Kurath G, Lamb RA, Lee B, Leroy EM, Li M, Maisner A, Mühlberger E, Netesov SV, Nowotny N, Patterson JL, Payne SL, Paweska JT, Pearson MN, Randall RE, Revill PA, Rima BK, Rota P, Rubbenstroth D, Schwemmle M, Smither SJ, Song Q, Stone DM, Takada A, Terregino C, Tesh RB, Tomonaga K, Tordo N, Towner JS, Vasilakis N, Volchkov VE, Wahl-Jensen V, Walker PJ, Wang B, Wang D, Wang F, Wang LF, Werren JH, Whitfield AE, Yan Z, Ye G, Kuhn JH. Taxonomy of the order Mononegavirales: update 2017. Arch Virol 2017 Aug;162(8):2493-504. http://dx.doi.org/10.1007/ s00705-017-3311-7. PubMed (https://www.ncbi.nlm.nih.gov/ pubmed/28389807)

14. Letchworth GJ, Rodriguez LL, Del cbarrera J. Vesicular stomatitis. Vet J 1999 May;157(3):239-60. http://dx.doi. org/10.1053/tvjl.1998.0303. PubMed (https://www.ncbi.nlm. nih.gov/pubmed/10328837)

15. Brandly CA, Hanson RP. Epizootiology of vesicular stomatitis. Am J Public Health Nations Health 1957 Feb;47(2):205-9. http://dx.doi.org/10.2105/AJPH.47.2.205. PubMed (https:// www.ncbi.nlm.nih.gov/pubmed/13394773)

16. Johnson KM, Vogel JE, Peralta PH. Clinical and serological response to laboratory-acquired human infection by Indiana type vesicular stomatitis virus (VSV). Am J Trop Med Hyg 1966 Mar;15(2):244-6. http://dx.doi.org/10.4269/ ajtmh.1966.15.244. PubMed (https://www.ncbi.nlm.nih.gov/ pubmed/4286381)

17. Brody JA, Fischer GF, Peralta PH. Vesicular stomatitis virus in Panama. Human serologic patterns in a cattle raising area. Am J Epidemiol 1967 Jul;86(1):158-61. http://dx.doi.org/10.1093/ oxfordjournals.aje.a120721. PubMed (https://www.ncbi.nlm. nih.gov/pubmed/4378113)

18. Whelan SP, Ball LA, Barr JN, Wertz GT. Efficient recovery of infectious vesicular stomatitis virus entirely from cDNA clones. Proc Natl Acad Sci USA 1995 Aug;92(18):8388-92. http:// dx.doi.org/10.1073/pnas.92.18.8388. PubMed (https://www. ncbi.nlm.nih.gov/pubmed/7667300)

19. Lawson ND, Stillman EA, Whitt MA, Rose JK. Recombinant vesicular stomatitis viruses from DNA. Proc Natl Acad Sci USA 1995 May;92(10):4477-81. http://dx.doi.org/10.1073/ pnas.92.10.4477. PubMed (https://www.ncbi.nlm.nih.gov/ pubmed/7753828)

20. Roberts A, Kretzschmar E, Perkins AS, Forman J, Price $\mathrm{R}$, Buonocore L, Kawaoka Y, Rose JK. Vaccination with a recombinant vesicular stomatitis virus expressing an influenza virus hemagglutinin provides complete protection from influenza virus challenge. J Virol 1998 Jun;72(6):4704-11. PubMed (https://www.ncbi.nlm.nih.gov/pubmed/9573234)

21. Haglund K, Forman J, Kräusslich HG, Rose JK. Expression of human immunodeficiency virus type 1 Gag protein precursor and envelope proteins from a vesicular stomatitis virus recombinant: high-level production of virus-like particles containing HIV envelope. Virology 2000 Mar;268(1):112-21. http://dx.doi.org/10.1006/viro.1999.0120. PubMed (https:// www.ncbi.nlm.nih.gov/pubmed/10683333)

22. Mire CE, Geisbert JB, Versteeg KM, Mamaeva N, Agans KN, Geisbert TW, Connor JH. A Single-Vector, Single-Injection Trivalent Filovirus Vaccine: Proof of Concept Study in Outbred Guinea Pigs. J Infect Dis 2015 Oct;212(Suppl 2):S384-8. http://dx.doi.org/10.1093/infdis/jiv126. PubMed (https:// www.ncbi.nlm.nih.gov/pubmed/25957964)

23. Johnson JE, Schnell MJ, Buonocore L, Rose JK. Specific targeting to CD4+ cells of recombinant vesicular stomatitis viruses encoding human immunodeficiency virus envelope proteins. J Virol 1997 Jul;71(7):5060-8. PubMed (https://www. ncbi.nlm.nih.gov/pubmed/9188571)

24. Kretzschmar E, Buonocore L, Schnell MJ, Rose JK. High-efficiency incorporation of functional influenza virus glycoproteins into recombinant vesicular stomatitis viruses. J Virol 1997 Aug;71(8):5982-9. PubMed (https://www.ncbi.nlm. nih.gov/pubmed/9223488)

25. Regules JA, Beigel JH, Paolino KM, Voell J, Castellano AR, Hu Z, Muñoz P, Moon JE, Ruck RC, Bennett JW, Twomey PS, Gutiérrez RL, Remich SA, Hack HR, Wisniewski ML, Josleyn MD, Kwilas SA, Van Deusen N, Mbaya OT, Zhou Y, Stanley DA, Jing W, Smith KS, Shi M, Ledgerwood JE, Graham BS, Sullivan NJ, Jagodzinski LL, Peel SA, Alimonti JB, Hooper JW, Silvera PM, Martin BK, Monath TP, Ramsey WJ, Link CJ, Lane HC, Michael NL, Davey RT Jr, Thomas SJ; rVSV $\triangle$ G-ZEBOV-GP Study Group. A Recombinant Vesicular Stomatitis Virus Ebola Vaccine. N Engl J Med 2017 Jan;376(4):330-41. http://dx.doi. org/10.1056/NEJMoa1414216. PubMed (https://www.ncbi. nlm.nih.gov/pubmed/25830322)

26. Freer G, Burkhart C, Ciernik I, Bachmann MF, Hengartner H, Zinkernagel RM. Vesicular stomatitis virus Indiana glycoprotein as a T-cell-dependent and -independent antigen. J Virol 1994 Jun;68(6):3650-5. 
27. Kündig TM, Castelmur I, Bachmann MF, Abraham D, Binder D, Hengartner H, Zinkernagel RM. Fewer protective cytotoxic T-cell epitopes than T-helper-cell epitopes on vesicular stomatitis virus [abstract]. J Virol 1993 Jun;67(6):3680-3. PubMed (https://www.ncbi.nlm.nih.gov/pubmed/7684471)

28. Zinkernagel RM, Adler B, Holland JJ. Cell-mediated immunity to vesicular stomatitis virus infections in mice. Exp Cell Biol 1978;46(1-2):53-70. PubMed (https://www.ncbi.nlm.nih.gov/ pubmed/202522)

29. Fuchs JD, Frank I, Elizaga ML, Allen M, Frahm N, Kochar N, Li S, Edupuganti S, Kalams SA, Tomaras GD, Sheets R, Pensiero M, Tremblay MA, Higgins TJ, Latham T, Egan MA, Clarke DK, Eldridge JH, HVTN 090 Study Group and the National Institutes of Allergy and Infectious Diseases HIV Vaccine Trials Network, Mulligan M, Rouphael N, Estep S, Rybczyk K, Dunbar D, Buchbinder S, Wagner T, Isbell R, Chinnell V, Bae J, Escamilla G, Tseng J, Fair R, Ramirez S, Broder G, Briesemeister L, Ferrara A. First-in-Human Evaluation of the Safety and Immunogenicity of a Recombinant Vesicular Stomatitis Virus Human Immunodeficiency Virus-1 gag Vaccine (HVTN 090). Open Forum Infect Dis 2015 Jun;2(3):ofv082. http://dx.doi.org/10.1093/ofid/ofv082. PubMed (https://www. ncbi.nlm.nih.gov/pubmed/26199949)

30. Henao-Restrepo AM, Camacho A, Longini IM, Watson $\mathrm{CH}_{\text {, }}$ Edmunds WJ, Egger M, Carroll MW, Dean NE, Diatta I, Doumbia M, Draguez B, Duraffour S, Enwere G, Grais R, Gunther S, Gsell PS, Hossmann S, Watle SV, Kondé MK, Kéita S, Kone S, Kuisma E, Levine MM, Mandal S, Mauget T, Norheim G, Riveros X, Soumah A, Trelle S, Vicari AS, Røttingen JA, Kieny MP. Efficacy and effectiveness of an rVSV-vectored vaccine in preventing Ebola virus disease: final results from the Guinea ring vaccination, open-label, cluster-randomised trial (Ebola Ça Suffit!). Lancet 2017 Feb;389(10068):505-18. http://dx.doi.org/10.1016/S0140-6736(16)32621-6. PubMed (https://www.ncbi.nlm.nih.gov/pubmed/28017403)

31. Garbutt M, Liebscher R, Wahl-Jensen $V$, Jones $S$, Möller P, Wagner R, Volchkov V, Klenk HD, Feldmann H, Ströher $U$. Properties of replication-competent vesicular stomatitis virus vectors expressing glycoproteins of filoviruses and arenaviruses. J Virol 2004 May;78(10):5458-65. http://dx.doi. org/10.1128/JVI.78.10.5458-5465.2004. PubMed (https:// www.ncbi.nlm.nih.gov/pubmed/15113924)

32. Geisbert TW, Jones S, Fritz EA, Shurtleff AC, Geisbert JB, Liebscher R, Grolla A, Ströher U, Fernando L, Daddario KM, Guttieri MC, Mothé BR, Larsen T, Hensley LE, Jahrling PB, Feldmann $H$. Development of a new vaccine for the prevention of Lassa fever. PLoS Med 2005 Jun;2(6):e183. http://dx.doi. org/10.1371/journal.pmed.0020183. PubMed (https://www. ncbi.nlm.nih.gov/pubmed/15971954)

33. Marzi A, Feldmann F, Geisbert TW, Feldmann H, Safronetz D. Vesicular stomatitis virus-based vaccines against Lassa and Ebola viruses. Emerg Infect Dis 2015 Feb;21(2):305-7. http:// dx.doi.org/10.3201/eid2102.141649. PubMed (https://www. ncbi.nlm.nih.gov/pubmed/25625358)

34. Bowen MD, Rollin PE, Ksiazek TG, Hustad HL, Bausch DG, Demby AH, Bajani MD, Peters CJ, Nichol ST. Genetic diversity among Lassa virus strains. J Virol 2000 Aug;74(15):6992-7004. http://dx.doi.org/10.1128/JVI.74.15.6992-7004.2000. PubMed (https://www.ncbi.nlm.nih.gov/pubmed/10888638)

35. Safronetz D, Mire C, Rosenke K, Feldmann F, Haddock E, Geisbert T, Feldmann H. A recombinant vesicular stomatitis virus-based Lassa fever vaccine protects guinea pigs and macaques against challenge with geographically and genetically distinct Lassa viruses. PLoS Negl Trop Dis 2015
Apr;9(4):e0003736. http://dx.doi.org/10.1371/journal. pntd.0003736. PubMed (https://www.ncbi.nlm.nih.gov/ pubmed/25884628)

36. Wong G, Mendoza EJ, Plummer FA, Gao GF, Kobinger GP, Qiu $X$. From bench to almost bedside: the long road to a licensed Ebola virus vaccine. Expert Opin Biol Ther 2018 Feb;18(2):15973. http://dx.doi.org/10.1080/14712598.2018.1404572. PubMed (https://www.ncbi.nlm.nih.gov/pubmed/29148858)

37. Mire CE, Geisbert TW, Feldmann H, Marzi A. Ebola virus vaccines - reality or fiction? Expert Rev Vaccines 2016 Nov;15(11):1421-30. http://dx.doi.org/10.1080/1476058 4.2016.1178068. PubMed (https://www.ncbi.nlm.nih.gov/ pubmed/27078187)

38. Reynolds P, Marzi A. Ebola and Marburg virus vaccines. Virus Genes 2017 Aug;53(4):501-15. http://dx.doi.org/10.1007/ s11262-017-1455-x. PubMed (https://www.ncbi.nlm.nih.gov/ pubmed/28447193)

39. Geisbert TW, Geisbert JB, Leung A, Daddario-DiCaprio KM, Hensley LE, Grolla A, Feldmann H. Single-injection vaccine protects nonhuman primates against infection with marburg virus and three species of ebola virus. J Virol 2009 Jul;83(14):7296-304. http://dx.doi.org/10.1128/JVI.00561-09. PubMed (https://www.ncbi.nlm.nih.gov/pubmed/19386702)

40. Mire CE, Geisbert JB, Marzi A, Agans KN, Feldmann H, Geisbert TW. Vesicular stomatitis virus-based vaccines protect nonhuman primates against Bundibugyo ebolavirus. PLoS Negl Trop Dis 2013 Dec;7(12):e2600. http://dx.doi. org/10.1371/journal.pntd.0002600. PubMed (https://www. ncbi.nlm.nih.gov/pubmed/24367715)

41. Marzi A, Engelmann F, Feldmann F, Haberthur K, Shupert WL, Brining D, Scott DP, Geisbert TW, Kawaoka Y, Katze MG, Feldmann H, Messaoudi I. Antibodies are necessary for rVSV/ZEBOV-GP-mediated protection against lethal Ebola virus challenge in nonhuman primates. Proc Natl Acad Sci USA 2013 Jan;110(5):1893-8. http://dx.doi.org/10.1073/ pnas.1209591110. PubMed (https://www.ncbi.nlm.nih.gov/ pubmed/23319647)

42. Mire CE, Geisbert JB, Agans KN, Satterfield BA, Versteeg KM, Fritz EA, Feldmann H, Hensley LE, Geisbert TW. Durability of a vesicular stomatitis virus-based marburg virus vaccine in nonhuman primates. PLoS One 2014 Apr;9(4):e94355. http:// dx.doi.org/10.1371/journal.pone.0094355. PubMed (https:// www.ncbi.nlm.nih.gov/pubmed/24759889)

43. Geisbert TW, Daddario-Dicaprio KM, Lewis MG, Geisbert JB, Grolla A, Leung A, Paragas J, Matthias L, Smith MA, Jones SM, Hensley LE, Feldmann H, Jahrling PB. Vesicular stomatitis virus-based ebola vaccine is well-tolerated and protects immunocompromised nonhuman primates. PLoS Pathog 2008 Nov;4(11):e1000225. http://dx.doi.org/10.1371/journal. ppat.1000225. PubMed (https://www.ncbi.nlm.nih.gov/ pubmed/19043556)

44. de Wit E, Marzi A, Bushmaker T, Brining D, Scott D, Richt JA, Geisbert TW, Feldmann H. Safety of recombinant VSV-Ebola virus vaccine vector in pigs. Emerg Infect Dis 2015 Apr;21(4):702-4. http://dx.doi.org/10.3201/eid2104.142012. PubMed (https://www.ncbi.nlm.nih.gov/pmc/articles/ PMC4378486/)

45. Huttner A, Dayer JA, Yerly S, Combescure C, Auderset F, Desmeules J, Eickmann M, Finckh A, Goncalves AR, Hooper JW, Kaya G, Krähling V, Kwilas S, Lemaître B, Matthey A, Silvera P, Becker S, Fast PE, Moorthy V, Kieny MP, Kaiser L, Siegrist CA; VSV-Ebola Consortium. The effect of dose on the safety and immunogenicity of the VSV Ebola candidate 
vaccine: a randomised double-blind, placebo-controlled phase 1/2 trial. Lancet Infect Dis 2015 Oct;15(10):1156-66. http://dx.doi.org/10.1016/S1473-3099(15)00154-1. PubMed (https://www.ncbi.nlm.nih.gov/pubmed/26248510)

46. Agnandji ST, Huttner A, Zinser ME, Njuguna P, Dahlke C, Fernandes JF, Yerly S, Dayer JA, Kraehling V, Kasonta R, Adegnika AA, Altfeld M, Auderset F, Bache EB, Biedenkopf N, Borregaard S, Brosnahan JS, Burrow R, Combescure C, Desmeules J, Eickmann M, Fehling SK, Finckh A, Goncalves AR, Grobusch MP, Hooper J, Jambrecina A, Kabwende AL, Kaya G, Kimani D, Lell B, Lemaître B, Lohse AW, Massinga-Loembe M, Matthey A, Mordmüller B, Nolting A, Ogwang C, Ramharter M, Schmidt-Chanasit J, Schmiedel S, Silvera P, Stahl FR, Staines HM, Strecker T, Stubbe HC, Tsofa B, Zaki S, Fast P, Moorthy V, Kaiser L, Krishna S, Becker S, Kieny MP, Bejon P, Kremsner PG, Addo MM, Siegrist CA. Phase 1 Trials of rVSV Ebola Vaccine in Africa and Europe. N Engl J Med 2016 Apr;374(17):1647-60. http://dx.doi.org/10.1056/ NEJMoa1502924. PubMed (https://www.ncbi.nlm.nih.gov/ pubmed/25830326)

47. ElSherif MS, Brown C, MacKinnon-Cameron D, Li L, Racine T, Alimonti J, Rudge TL, Sabourin C, Silvera P, Hooper JW, Kwilas SA, Kilgore N, Badorrek C, Ramsey WJ, Heppner DG, Kemp T, Monath TP, Nowak T, McNeil SA, Langley JM, Halperin SA; Canadian Immunization Research Network. Assessing the safety and immunogenicity of recombinant vesicular stomatitis virus Ebola vaccine in healthy adults: a randomized clinical trial. CMAJ 2017 Jun;189(24):E819-27. http://dx.doi. org/10.1503/cmaj.170074. PubMed (https://www.ncbi.nlm. nih.gov/pubmed/28630358)

48. Agnandji ST, Fernandes JF, Bache EB, Obiang Mba RM, Brosnahan JS, Kabwende L, Pitzinger P, Staarink P, Massinga-Loembe M, Krähling V, Biedenkopf N, Fehling SK, Strecker T, Clark DJ, Staines HM, Hooper JW, Silvera P, Moorthy V, Kieny MP, Adegnika AA, Grobusch MP, Becker S, Ramharter M, Mordmüller B, Lell B; VEBCON Consortium, Krishna S, Kremsner PG. Safety and immunogenicity of rVSVDG-ZEBOV-GP Ebola vaccine in adults and children in Lambaréné, Gabon: A phase I randomised trial. PLoS Med 2017 Oct;14(10):e1002402. http://dx.doi.org/10.1371/journal. pmed.1002402. PubMed (https://www.ncbi.nlm.nih.gov/ pubmed/28985239)

49. Halperin SA, Arribas JR, Rupp R, Andrews CP, Chu L, Das R, Simon JK, Onorato MT, Liu K, Martin J, Helmond FA; V920-012 Study Team. Six-Month Safety Data of Recombinant Vesicular Stomatitis Virus-Zaire Ebola Virus Envelope Glycoprotein Vaccine in a Phase 3 Double-Blind, Placebo-Controlled Randomized Study in Healthy Adults. J Infect Dis 2017 Jun;215(12):1789-98. http://dx.doi.org/10.1093/infdis/jix189. PubMed (https://www.ncbi.nlm.nih.gov/pubmed/28549145)

50. Lukashevich IS, Pushko P. Vaccine platforms to control Lassa fever. Expert Rev Vaccines 2016 Sep;15(9):1135-50. http:// dx.doi.org/10.1080/14760584.2016.1184575. PubMed (https://www.ncbi.nlm.nih.gov/pubmed/27136941)

51. Lukashevich IS. Advanced vaccine candidates for Lassa fever. Viruses 2012 Oct;4(11):2514-57. http://dx.doi.org/10.3390/ v4112514. PubMed (https://www.ncbi.nlm.nih.gov/pmc/ articles/PMC3509661/)

52. Fisher-Hoch SP, Hutwagner L, Brown B, McCormick JB. Effective vaccine for lassa fever. J Virol 2000 Aug;74(15):677783. http://dx.doi.org/10.1128/JVI.74.15.6777-6783.2000. PubMed (https://www.ncbi.nlm.nih.gov/pubmed/10888616)

53. Morrison HG, Bauer SP, Lange JV, Esposito JJ, McCormick $J B$, Auperin DD. Protection of guinea pigs from Lassa fever by vaccinia virus recombinants expressing the nucleoprotein or the envelope glycoproteins of Lassa virus. Virology 1989 Jul;171(1):179-88. http://dx.doi.org/10.1016/00426822(89)90525-4. PubMed (https://www.ncbi.nlm.nih.gov/ pubmed/2741340)

54. Fisher-Hoch SP, McCormick JB, Auperin D, Brown BG, Castor M, Perez G, Ruo S, Conaty A, Brammer L, Bauer S. Protection of rhesus monkeys from fatal Lassa fever by vaccination with a recombinant vaccinia virus containing the Lassa virus glycoprotein gene. Proc Natl Acad Sci USA 1989 Jan;86(1):317-21. http://dx.doi.org/10.1073/pnas.86.1.317. PubMed (https://www.ncbi.nlm.nih.gov/pubmed/2911575)

55. Auperin DD, Esposito JJ, Lange JV, Bauer SP, Knight J, Sasso DR, McCormick JB. Construction of a recombinant vaccinia virus expressing the Lassa virus glycoprotein gene and protection of guinea pigs from a lethal Lassa virus infection. Virus Res 1988 Feb;9(2-3):233-48. http://dx.doi. org/10.1016/0168-1702(88)90033-0. PubMed (https://www. ncbi.nlm.nih.gov/pubmed/3354260)

56. Clegg JC, Lloyd G. Vaccinia recombinant expressing Lassa-virus internal nucleocapsid protein protects guineapigs against Lassa fever. Lancet 1987 Jul;2(8552):186-8. http:// dx.doi.org/10.1016/S0140-6736(87)90767-7. PubMed (https://www.ncbi.nlm.nih.gov/pubmed/2885642)

57. Jiang X, Dalebout TJ, Bredenbeek PJ, Carrion R Jr, Brasky K, Patterson J, Goicochea M, Bryant J, Salvato MS, Lukashevich IS. Yellow fever 17D-vectored vaccines expressing Lassa virus GP1 and GP2 glycoproteins provide protection against fatal disease in guinea pigs. Vaccine 2011 Feb;29(6):1248-57. http://dx.doi.org/10.1016/j.vaccine.2010.11.079. PubMed (https://www.ncbi.nlm.nih.gov/pubmed/21145373)

58. Bredenbeek PJ, Molenkamp R, Spaan WJ, Deubel V, Marianneau P, Salvato MS, Moshkoff D, Zapata J, Tikhonov I, Patterson J, Carrion R, Ticer A, Brasky K, Lukashevich IS. A recombinant Yellow Fever 17D vaccine expressing Lassa virus glycoproteins. Virology 2006 Feb;345(2):299-304. http:// dx.doi.org/10.1016/j.virol.2005.12.001. PubMed (https:// www.ncbi.nlm.nih.gov/pubmed/16412488)

59. McCormick JB, Mitchell SW, Kiley MP, Ruo S, Fisher-Hoch SP. Inactivated Lassa virus elicits a non protective immune response in rhesus monkeys. J Med Virol 1992 May;37(1):1-7. http://dx.doi.org/10.1002/jmv.1890370102. PubMed (https:// www.ncbi.nlm.nih.gov/pubmed/1619397)

60. Wang M, Jokinen J, Tretyakova I, Pushko P, Lukashevich IS. Alphavirus vector-based replicon particles expressing multivalent cross-protective Lassa virus glycoproteins. Vaccine 2018 Jan;36(5):683-90. http://dx.doi.org/10.1016/j. vaccine.2017.12.046. PubMed (https://www.ncbi.nlm.nih.gov/ pubmed/29287681)

61. Pushko P, Geisbert J, Parker M, Jahrling P, Smith J. Individual and bivalent vaccines based on alphavirus replicons protect guinea pigs against infection with Lassa and Ebola viruses. J Virol 2001 Dec;75(23):11677-85. http://dx.doi.org/10.1128/ JVI.75.23.11677-11685.2001. PubMed (https://www.ncbi.nlm. nih.gov/pubmed/11689649)

62. Pushko P, Parker M, Ludwig GV, Davis NL, Johnston RE, Smith JF. Replicon-helper systems from attenuated Venezuelan equine encephalitis virus: expression of heterologous genes in vitro and immunization against heterologous pathogens in vivo. Virology 1997 Dec;239(2):389-401. http://dx.doi. org/10.1006/viro.1997.8878. PubMed (https://www.ncbi.nlm. nih.gov/pubmed/9434729) 
63. Cashman KA, Broderick KE, Wilkinson ER, Shaia Cl, Bell TM, Shurtleff AC, Spik KW, Badger CV, Guttieri MC, Sardesai NY Schmaljohn CS. Enhanced Efficacy of a Codon-Optimized DNA Vaccine Encoding the Glycoprotein Precursor Gene of Lassa Virus in a Guinea Pig Disease Model When Delivered by Dermal Electroporation. Vaccines (Basel) 2013 Jul;1(3):262-77. http://dx.doi.org/10.3390/vaccines1030262. PubMed (https://www.ncbi.nlm.nih.gov/pubmed/26344112)

64. Cashman KA, Wilkinson ER, Shaia Cl, Facemire PR, Bell TM, Bearss JJ, Shamblin JD, Wollen SE, Broderick KE, Sardesai NY, Schmaljohn CS. A DNA vaccine delivered by dermal electroporation fully protects cynomolgus macaques against Lassa fever. Hum Vaccin Immunother 2017 Dec;13(12):290211. http://dx.doi.org/10.1080/21645515.2017.1356500. PubMed (https://www.ncbi.nlm.nih.gov/pubmed/29045192)

65. Cashman KA, Wilkinson ER, Wollen SE, Shamblin JD, Zelko JM, Bearss JJ, Zeng X, Broderick KE, Schmaljohn CS. DNA vaccines elicit durable protective immunity against individual or simultaneous infections with Lassa and Ebola viruses in guinea pigs. Hum Vaccin Immunother 2017 Dec;13(12):3010-9. http://dx.doi.org/10.1080/21645515.2017.1382780. PubMed (https://www.ncbi.nlm.nih.gov/pubmed/29135337)

66. Moshkoff DA, Salvato MS, Lukashevich IS. Molecular characterization of a reassortant virus derived from Lassa and Mopeia viruses. Virus Genes 2007 Apr;34(2):169-76. http:// dx.doi.org/10.1007/s11262-006-0050-3. PubMed (https:// www.ncbi.nlm.nih.gov/pubmed/17143722)

67. Goicochea MA, Zapata JC, Bryant J, Davis H, Salvato MS, Lukashevich IS. Evaluation of Lassa virus vaccine immunogenicity in a CBA/J-ML29 mouse model. Vaccine 2012 Feb;30(8):1445-52. http://dx.doi.org/10.1016/j. vaccine.2011.12.134. PubMed (https://www.ncbi.nlm.nih.gov/ pubmed/22234266)

68. Lukashevich IS, Carrion R Jr, Salvato MS, Mansfield K, Brasky K, Zapata J, Cairo C, Goicochea M, Hoosien GE, Ticer A, Bryant J, Davis H, Hammamieh R, Mayda M, Jett M, Patterson J. Safety, immunogenicity, and efficacy of the ML29 reassortant vaccine for Lassa fever in small non-human primates. Vaccine 2008 Sep;26(41):5246-54. http://dx.doi.org/10.1016/j. vaccine.2008.07.057. PubMed (https://www.ncbi.nlm.nih.gov/ pubmed/18692539)

69. Jahrling PB, Frame JD, Rhoderick JB, Monson MH. Endemic Lassa fever in Liberia. IV. Selection of optimally effective plasma for treatment by passive immunization. Trans R Soc Trop Med Hyg 1985;79(3):380-4. http://dx.doi. org/10.1016/0035-9203(85)90388-8. PubMed (https://www. ncbi.nlm.nih.gov/pubmed/3898484)

70. Lukashevich IS, Patterson J, Carrion R, Moshkoff D, Ticer A, Zapata J, Brasky K, Geiger R, Hubbard GB, Bryant J, Salvato MS. A live attenuated vaccine for Lassa fever made by reassortment of Lassa and Mopeia viruses. J Virol 2005 Nov;79(22):13934-42. http://dx.doi.org/10.1128/ JVI.79.22.13934-13942.2005. PubMed (https://www.ncbi.nlm. nih.gov/pubmed/16254329)

71. Lukashevich IS. Generation of reassortants between African arenaviruses. Virology 1992 Jun;188(2):600-5. http://dx.doi. org/10.1016/0042-6822(92)90514-P. PubMed (https://www. ncbi.nlm.nih.gov/pubmed/1585636)

72. Zapata JC, Poonia B, Bryant J, Davis H, Ateh E, George L, Crasta O, Zhang Y, Slezak T, Jaing C, Pauza CD, Goicochea M, Moshkoff D, Lukashevich IS, Salvato MS. An attenuated Lassa vaccine in SIV-infected rhesus macaques does not persist or cause arenavirus disease but does elicit Lassa virus-specific immunity. Virol J 2013 Feb;10:52. http://dx.doi. org/10.1186/1743-422X-10-52. PubMed (https://www.ncbi. nlm.nih.gov/pubmed/23402317)

73. Carrion R Jr, Patterson JL, Johnson C, Gonzales M, Moreira CR, Ticer A, Brasky K, Hubbard GB, Moshkoff D, Zapata J, Salvato MS, Lukashevich IS. A ML29 reassortant virus protects guinea pigs against a distantly related Nigerian strain of Lassa virus and can provide sterilizing immunity. Vaccine 2007 May;25(20):4093-102. http://dx.doi.org/10.1016/j. vaccine.2007.02.038. PubMed (https://www.ncbi.nlm.nih.gov/ pubmed/17360080)

74. World Health Organization. A research and development Blueprint for action to prevent epidemics. WHO; 2018. www. who.int/blueprint/en/

75. Baize S, Marianneau P, Loth P, Reynard S, Journeaux A, Chevallier M, Tordo N, Deubel V, Contamin H. Early and strong immune responses are associated with control of viral replication and recovery in lassa virus-infected cynomolgus monkeys. J Virol 2009 Jun;83(11):5890-903. http://dx.doi. org/10.1128/JVI.01948-08. PubMed (https://www.ncbi.nlm. nih.gov/pubmed/19297492)

76. Meulen J, Badusche M, Satoguina J, Strecker T, Lenz O, Loeliger C, Sakho M, Koulemou K, Koivogui L, Hoerauf A. Old and New World arenaviruses share a highly conserved epitope in the fusion domain of the glycoprotein 2, which is recognized by Lassa virus-specific human CD4+ T-cell clones. Virology 2004 Mar;321(1):134-43. http://dx.doi.org/10.1016/j. virol.2003.12.013. PubMed (https://www.ncbi.nlm.nih.gov/ pubmed/15033572)

77. ter Meulen J, Badusche M, Kuhnt K, Doetze A, Satoguina J, Marti T, Loeliger C, Koulemou K, Koivogui L, Schmitz H, Fleischer B, Hoerauf A. Characterization of human CD4(+) T-cell clones recognizing conserved and variable epitopes of the Lassa virus nucleoprotein. J Virol 2000 Mar;74(5):2186-92. http://dx.doi.org/10.1128/JVI.74.5.2186-2192.2000. PubMed (https://www.ncbi.nlm.nih.gov/pubmed/10666248)

78. Russier M, Pannetier D, Baize S. Immune responses and Lassa virus infection. Viruses 2012 Nov;4(11):2766-85. http://dx.doi. org/10.3390/v4112766. PubMed (https://www.ncbi.nlm.nih. gov/pubmed/23202504)

79. Walker DH, Johnson KM, Lange JV, Gardner JJ, Kiley MP, McCormick JB. Experimental infection of rhesus monkeys with Lassa virus and a closely related arenavirus, Mozambique virus. J Infect Dis 1982 Sep;146(3):360-8. http://dx.doi. org/10.1093/infdis/146.3.360. PubMed (https://www.ncbi. nlm.nih.gov/pubmed/6286795)

80. Fisher-Hoch SP, Mitchell SW, Sasso DR, Lange JV, Ramsey R, McCormick JB. Physiological and immunologic disturbances associated with shock in a primate model of Lassa fever. J Infect Dis 1987 Mar;155(3):465-74. http://dx.doi.org/10.1093/ infdis/155.3.465. PubMed (https://www.ncbi.nlm.nih.gov/ pubmed/3543155)

81. Johnson KM, McCormick JB, Webb PA, Smith ES, Elliott $\mathrm{LH}$, King IJ. Clinical virology of Lassa fever in hospitalized patients. J Infect Dis 1987 Mar;155(3):456-64. http://dx.doi. org/10.1093/infdis/155.3.456. PubMed (https://www.ncbi. nlm.nih.gov/pubmed/3805773)

82. Cohen J. Unfilled Vials. Science 2016 Jan;351(6268):16-9. http://dx.doi.org/10.1126/science.351.6268.16. PubMed (https://www.ncbi.nlm.nih.gov/pubmed/26721985) 